\title{
Towards attaining the recommended Humanitarian Sphere Standards of sanitation in Bidibidi refugee camp found in Yumbe District, Uganda
}

\author{
Zaitun Bako ${ }^{1}$, Alex Barakagira ${ }^{1,2^{*}}$ and Ameria Nabukonde
}

\begin{abstract}
Adequate sanitation is one of the most important aspects of community well-being. It reduces the rates of morbidity and severity of various diseases like diarrhea, dysentery, and typhoid among others. A study about toward the attainment of the recommended Humanitarian Sphere Standards on sanitation in Bidibidi refugee camp, Yumbe District, was initiated. A total of 210 households distributed in Bidibidi refugee camp were randomly selected and one adult person interviewed to assess the accessibility of different sanitation facilities, and to explore the sanitation standards of the sanitation facilities in relation to the recommended Humanitarian Sphere Standards in the area. Pit latrines, hand washing facilities, and solid waste disposal areas as reported by $81.4 \%, 86.7 \%$, and $51.9 \%$ of the respondents respectively, are the main sanitation facilities accessed in the refugee camp. Despite their accessibility, the standards of the pit latrines, hand washing, and solid waste disposal facilities are below the recommended standards, which might have contributed to the outbreak of sanitation related diseases $\left(x^{2}=19.66\right.$, $\mathrm{df}=1, \mathrm{P}=0.05)$ in Bidibidi refugee camp. The respondents in the study area were aware that the presence of the sanitation-related diseases was because of the low-level sanitation practices in place $\left(X^{2}=4.54, \mathrm{df}=1, P=0.05\right)$. The inaccessibility to some sanitation facilities by some respondents was found to be related to their low level of education $\left(X^{2}=130.37, d f=1, P=0.05\right)$. This implies that the sanitation facilities in Bidibidi refugee camp need to be redesigned and improved especially the pit latrines and the solid waste disposal facilities in order to meet the minimum Humanitarian Sphere Standards. Also, there should be more provision of taps with flowing water in the camp for effective washing practices to minimize the spread of sanitation-related diseases.
\end{abstract}

Keywords: Critical infrastructures, Humanitarian Sphere Standards, Refugees, Bidibidi, Uganda

\section{Introduction}

Sanitation is one of the most important aspects of community well-being (Mara et al. 2010; Naughton and Mihelcic 2017), which in most cases is deployed as a way to contain or treat human excreta to protect human health and environment (Cairncross and Valdmanis 2006; Naughton and Mihelcic 2017; WHO 2017).

\footnotetext{
* Correspondence: abarakagira@kyu.ac.ug

${ }^{1}$ School of Sciences, Nkumba University, P.O. Box 237, Entebbe, Uganda

${ }^{2}$ Faculty of Science, Kyambogo University, P.O. Box 1, Kyambogo, Kampala, Uganda
}

Adequate sanitation creates the first barrier to excretarelated disease, helping to reduce transmission through direct and indirect routes (The Sphere Project 2004). rovement in sanitation reduces the rates of morbidMoe and Rheingans 2006; WHO 2017).

Worldwide, the WHO and UNICEF (2015) state that over one billion people still practice open defecation, which account for an estimated 9.1 percent of the global burden of disease (in disability-adjusted life years or 
DALYS) and 6.3 percent of all deaths (Pruss-Ustun et al. 2008). Eliasson (2013) intimate that poor sanitation coupled with lack of access to safe drinking water, results in economic losses and accounts for about 40006000 children that die each day (Bill and Melinda 2016; Moe and Rheingans 2006; WSSCC 2004). The global burden of poor sanitation as reported by UNICEF and WHO (2004) falls primarily on the poorest of the poor, and in this case, refugees are not spared. Moe and Rheingans (2006) reported that in sub-Saharan Africa, only $36 \%$ of the population has access to basic sanitation and it is likely to be worse in refugee camps, hence, escalating the spread of sanitation-related diseases. Mulogo et al. (2018) state that inadequate sanitation in non-household setting like refugee camps negatively impacts the health, education, and welfare of the populations. Therefore, investing in good sanitation activities is likely to save lives of human beings. This is because in the study carried out by the WHO (2012), it was reported that for every $\$ 1$ invested in sanitation, there was a return of $\$ 5.50$ in lower health costs, more productivity, and fewer premature deaths.

Safe excreta disposal should be a major priority in most disaster situations including refugee camps to curb the spread of poor-sanitation-related diseases (The Sphere Project 2004). This is because, people affected by crises are more susceptible to illness and death from disease, particularly diarrheal and infectious diseases which are strongly related to inadequate sanitation and water supplies (Mara et al. 2010).

The Sphere Minimum Standards specify the minimum levels to be attained in the provision of health and relief services and also provide a way of measuring and communicating the impact of programs as well as the methods used (Griekspoor and Collins 2001; The Sphere Project 2004; WHO 2013). Griekspoor and Collins (2001) add that the Sphere project aims at establishing a technical and possible actions for relief operations for humanitarian communities. Also, the Sustainable Development Goal 6 for 2030 aims to achieve adequate sanitation for all and end open defecation (Naughton and Mihelcic 2017). Fekete et al. (2021) state that minimum standards for critical infrastructures in places where displaced people live are very essential for the prevention of adverse health effects, since according to Sendai Framework for Disaster Risk Reduction by the United Nations, the standards are a backbone for the provision of vital health services. Despite the call, the world fell short of basic sanitation by over one billion people particularly in Asia and sub-Saharan Africa (Naughton and Mihelcic 2017; WHO/UNICEF JMP 2015) and this is likely to be more pronounced in refugee camps.

Bidibidi refugee camp located in Yumbe District that is about $17 \mathrm{~km}$ to the border with South Sudan houses over 214,000 refugees. The district receives about 2000 new arrivals on daily basis (UNHCR 2016). This therefore calls for installation of sanitation facilities that are adequate enough to provide services for the surging numbers of refugees in the camp aimed at preventing any outbreak of diseases that may be related to inadequate or poor sanitation. In order to achieve this, the guidelines as spelt out by the Humanitarian Sphere Minimum Standards must be followed by the individuals concerned when implementing the provision of the sanitation facilities in Bidibidi refugee camp. The purpose of the study was therefore to assess whether the sanitation facilities found in Bidibidi refugee camp conform to the Humanitarian Sphere Minimum Standards as a way of preventing the outbreak of sanitation-related diseases. Two objectives guided the study which include the following:

i. Assessing the accessibility of different sanitation facilities by the refugees found in Bidibidi refugee camp.

ii. Exploring sanitation standards in relation to the Humanitarian Sphere Standards in Bidibidi refugee camp.

\section{Study area}

The study focused on Bidibidi refugee camp found in Yumbe District, north western Uganda (Fig. 1). The district is bordered by South Sudan to the north, Moyo District to the east, Adjumani District to the south-east, Arua District to the south, Maracha District to the south-west and Koboko District to the west. Yumbe District is at coordinates $0328 \mathrm{~N}, 3115 \mathrm{E}$ and it is about $17 \mathrm{~km}$ from the border of South Sudan, the youngest country in the world.

Yumbe District is made of thirteen sub-Counties which include Odravu, Kululu, Ariwa, Romogi, Kei, Kuru, Kochi, Town Council, Midigo, Kerwa, Lodonga, Drajini, and Apo. Five of these sub-Counties including Romogi, Apo, Odravu, Ariwa, and Kululu have refugee camps. Bidibidi zone is located in Romogi and Apo subCounties where the research was conducted. Bidibidi zone was selected for the study because it was the first established zone and has the largest refugee population in Yumbe district with about 56,000 refugees settled (UNHCR 2016). Bidibidi zone is further made of fourteen villages and it is more stable in terms of infrastructure like roads, water, and electricity among others, and hence can avail credible data needed for the study.

\section{Materials and methods}

The research project focused on determining whether sanitation standards in refugee camps especially in Bidibidi refugee camp found in Yumbe District are being 


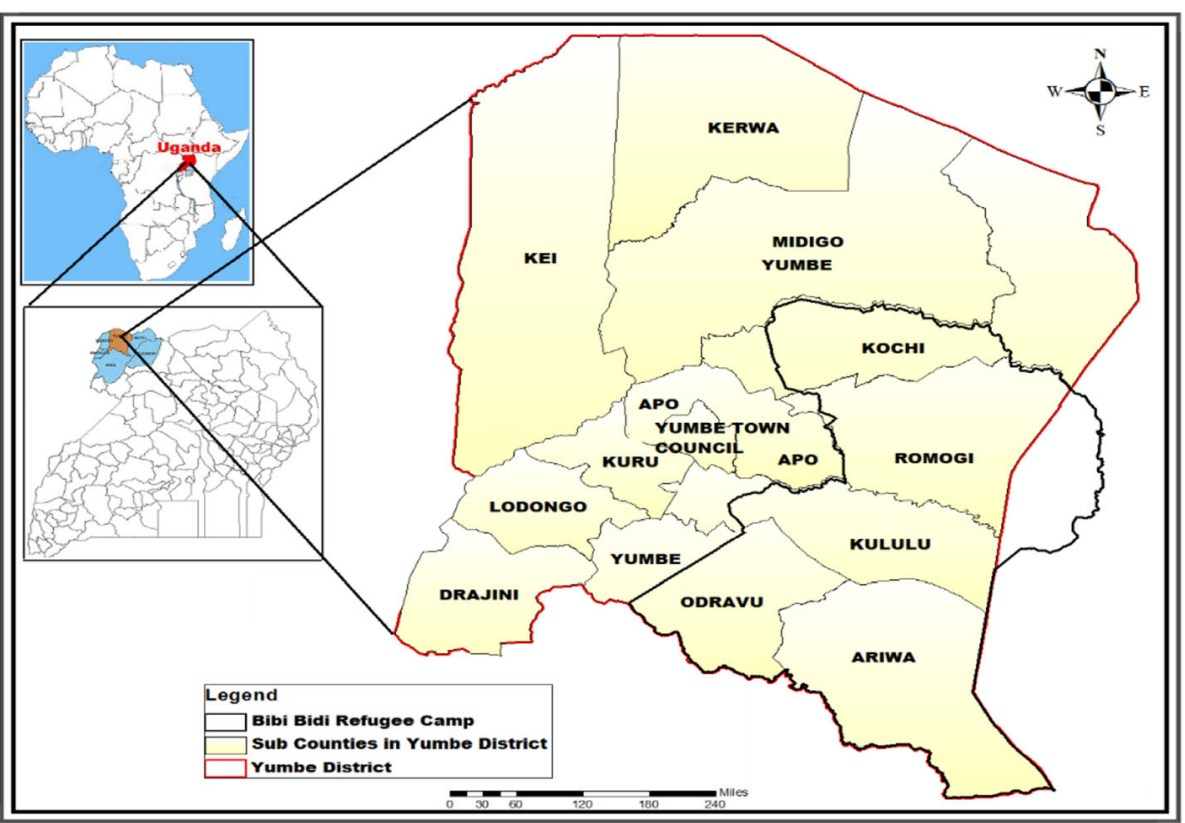

Fig. 1 Map of Uganda showing the location of Bidibidi zone

attained, compared to the Humanitarian Minimum Sphere Standards. The study aimed at assessing the accessibility of different sanitation facilities found in Bidibidi refugee camp, and to explore sanitation standards in comparison to the Humanitarian Sphere Standards in Bidibidi refugee camp found in Yumbe District. Both qualitative and quantitative data was obtained from the respondents in order to generate the information needed for determining whether sanitation standards in Bidibidi refugee camp are being attained in comparison with the Humanitarian Minimum Sphere Standards. Sarantakos (2005) and Lindlof and Taylor (2011) reported that qualitative data is used to verify and enrich the quantitative data obtained from the study. Other complementary methods like observation were used to collect a vast amount of data with the advantage that the methods enhanced the capacity for interpreting the data captured as suggested by Hoggart et al. (2002).

A questionnaire (Additional file 1) was used to collect primary data from the respondents in the study area, while the semi-structured interviews were used to collect the qualitative data from the key informants like staff from department of health, water, natural resources, and education, UNHCR and its implementing agencies like NRC, Uganda Red Cross Society, Oxfam, and Samaritan Purse.

The questionnaire used to collect data from the refugees was pre-tested in one of the other refugee camps apart from Bidibidi. Pre-testing allowed the interviewers to gain familiarity with the questionnaire and provided an opportunity to apply and review the method. The focus was on assessing how the respondents understood the questions and to identify any problems encountered in providing answers. Changes were proposed, reviewed, and incorporated into the final questionnaire. The questionnaire focused on the respondents' understanding of the sanitation standards in relation to the Humanitarian Minimum Sphere Standards in Bidibidi refugee camp.

A questionnaire survey was conducted among two hundred and ten households which were randomly selected. There are fourteen villages consisting of thirty households each in Bidibidi refugee camp. This gives a total of 420 households in the entire Bidibidi refugee camp. Using Yamane (1967) formula, $\mathrm{n}=\mathrm{N} / 1+\mathrm{Ne}^{2}$, where $\mathrm{n}=$ sample size, $\mathrm{N}=$ total number of households (420), e = level of confidence (0.05), the calculated sample size $(n)=420 / 1+420(0.05)^{2}=205$. If equal number of households were to be selected from the 14 villages, then 14.6 households would be selected. The figure (14.6 households) was rounded off to 15 households. This meant that 15 households selected from each village gave a total of 210 households which were used as a representative sample in the study. Therefore, fifteen (15) households were randomly selected from each village to include in the study. One adult person (18 years and above) from each household was then selected, approached, briefed, and informed that the purpose of the research was purely academic and had no implications whatsoever, and that the respondents were also assured of 
confidentiality and anonymity. The questionnaire was then administered to the respondent which in most cases was semi-structured in the common language, since majority (65\%) had not attained secondary level of education and their level of comprehension of the information in the questionnaire was regarded as low (Table 1). The response rate of the respondents was 100\% since at least one adult person was present in the selected household at the time of collecting data.

A semi-structured interview guide was also designed and administered to some members of staff who occupy managerial positions in the department of health, water, natural resources, and education, UNHCR and the implementing agencies who were purposively selected as suggested by Hyman et al. (2001) and Sarantakos (2005). The aim was to gather more information concerning sanitation standards in relation to the Humanitarian Minimum Sphere Standards in Bidibidi refugee camp.

In addition, direct field observations were made to check on sanitation facilities that existed in the camp, their conditions and quality. This was done with the help of observation checklist that was developed to guide in data collection. Direct field observations were also used to verify the reliability of the information the research participants had provided to the researcher regarding the study topic. The state of the sanitation facilities was depicted with the help of digital photographs.

Questionnaire responses were edited, coded, and analyzed using SPSS version 16.0 for windows. These informed descriptive statistics concerning sanitation standards in Bidibidi refugee camp. The analyzed data was then accompanied with notes to direct readers' attention to important values for comparison. Percentage values were used to relate what is in the frequency distribution tables together with the likely cause of the outcome. Generalization of the data was made while reporting on the data based on the percentages obtained for particular items in the survey. Generalization as reported by Bryman (2004) and Sarantakos (2005) ensures extrapolation of the research findings beyond the boundaries of the research sample to the whole population.
Qualitative data collected during key informant interviews was sorted and categorized into themes according to particular items of interest as reported by Sarantakos (2005). In cases where the research participant gave a narrative for a particular response, efforts were made to reproduce the actual words, or conversations that were given from the field, based on the popular themes of the study. In some cases, the chi-square test was used to test for association of attributes.

\section{Results}

\section{Accessibility of sanitation facilities}

There are different types of sanitation facilities found in Bidibidi refugee camp. The sanitation facilities as reported by the respondents including pit latrines (81.4\%), hand washing facilities after toilet use (86.7\%), and solid waste disposal pits (51.9\%). Focusing on the sanitation facilities found in Bidibidi refugee camp, their accessibility was implored as presented in Table 1.

The sanitation facilities found in Bidibidi refugee camp are accessible to most respondents. About 68\% $(n=117)$ of the respondents stated that the latrines are located within a distance of $30 \mathrm{~m}$ from their places of residence, while about $32 \%(n=54)$ respondents reported that their latrines are located at a distance of more than 30 $\mathrm{m}$. This implies that majority (68\%) of the latrines in the refugee camp are accessible since they are located within a distance of $50 \mathrm{~m}$ from the places of dwellings as stated in the Sphere Minimum Standards. The latrines which are less accessible do not encourage the residents to use them. This forces the residents to use alternatives like the bush (open defecation), buckets or plastic containers, polythene bags (flying toilets), and sharing of latrines. The inappropriate disposal of the fecal matter by this section of members of the refugees could have accounted for the outbreak of some sanitation related diseases like diarrhea (36.9\%), typhoid (22.4\%), cholera (7.9), and dysentery (6.1\%) in the refugee camp. It was however revealed that accessibility to sanitation facilities was associated with the educational level of respondents $\left(X^{2}=130.37, \mathrm{df}=1, \mathrm{P}=0.05\right)$ from Bidibidi refugee

Table 1 Accessibility of sanitation facilities in Bidibidi refugee camp (researchers' questionnaire survey)

\begin{tabular}{llll}
\hline Sanitation facility & Accessibility & Frequency & Percent \\
\hline Pit latrines & Less than $30 \mathrm{~m}$ & 117 & 54 \\
& More than $30 \mathrm{~m}$ & 159 & 31.6 \\
Hand washing facility & Near; $<5 \mathrm{~m}$ from latrine & 23 & 13.9 \\
& Distant; $>5 \mathrm{~m}$ from latrine & 62 & 37.9 \\
Solid waste disposal area & Near; $<10 \mathrm{~m}$ from residence & 31 & 28.7 \\
& Distant; $10-15 \mathrm{~m}$ from residence & 16 & 14.8 \\
\hline
\end{tabular}


camp. This implies that the more educated the respondents in the refugee camp, the more access to sanitation facilities and hence the less outbreaks of the sanitationrelated diseases. The inaccessibility to some sanitation facilities in Bidibidi refugee camp was attributed to the low levels of education of majority (65\%) of the respondents. This was probably because of lack of some requisite knowledge by the respondents about the dangers of inadequate sanitation facilities near their dwellings.

In addition, latrine inaccessibility to some respondents was associated with the outbreak of sanitation-related diseases $\left(X^{2}=19.66, \mathrm{df}=1, \mathrm{P}=0.05\right)$ in Bidibidi refugee camp. This is in agreement with one of the sanitation health officers' statement that:

The main sanitation related diseases in the camp include diarrhea, dysentery, malaria and cholera that accounted for the 52 cases recorded in one month.

Another test was conducted to determine whether the respondents' awareness of the existence of sanitation related diseases were associated with the low state of sanitation. The study revealed that the respondents' awareness of the existence of sanitation-related diseases was associated with the low state of sanitation $\left(x^{2}=\right.$ 4.54 , $\mathrm{df}=1, \mathrm{P}=0.05)$ in Bidibidi refugee camp. This implies that despite the respondents having knowledge about the existence of diseases brought about by inappropriate sanitation practices, diseases still cropped up because of poor fecal disposal. This was probably because of some individuals' beliefs like not supposed to dispose of their fecal matter in latrines while others had a belief that they are not supposed to share pit latrines and, in some cases, they did not have their own, leaving them with no alternative but open defecation. Some other respondents were elderly and could not construct for themselves pit latrines, and that they were still waiting for some agencies to help and construct for them pit latrines. Other elderly individuals were reported to have difficulty in squirting on pit latrines which compelled them to defecate in open grounds.

\section{Standards of sanitation facilities in the study area}

The standards of sanitation facilities including pit latrines, hand washing, and solid waste disposal in Bidibidi refugee camp were explored. Slightly over a half (59.6\%) of respondents reported that the pit latrines found in Bidibidi refugee camp are not shared, while $40.4 \%$ of the respondents stated that they share the use of the pit latrines. The study further revealed that among the shared pit latrines, $29.9 \%(n=51)$ of the respondents having an average of three members in each household share the use of pit latrines. A smaller percentage $(6.4 \% ; n=11)$ of respondents having at least 11 members in each household share the use of pit latrines (Table 2).

When the pit latrines are shared, there is a likelihood that they will not be attended to, especially in terms of cleaning them. When they are not well cleaned, they tend to house the pests which may contribute to the spread of the sanitation-related diseases.

In addition, the quality of pit latrines that are used in Bidibidi refugee camp was also explored (Table 3). The study focused on the building materials used to construct the pit latrines.

Pit latrines as one of the sanitation facilities in Bidibidi refugee camp were constructed using different building materials. It was revealed that almost half (49.7\%) of the pit latrines had a slab made out of wattle and mud, followed by those pit latrines $(25.7 \%)$ whose slab is made of plastic. The pit latrines with a slab made of iron bars and cement and are regarded as strongest were represented by a small proportion of $14 \%$ only.

The walls or the side screens of most pit latrines (37.4\%) were made using papyrus (reeds) and old tarpaulins, and these are temporally materials as observed in Plate 1 and were almost the same in number (33.9\%) as those whose walls were built using bricks and cement (Plate 2).

It was observed that some pit latrines lacked covering lids, others' floor were laid using wood and mud, while some others used temporally screens which worked as pit latrine wall. Such types of walls were not able to offer maximum privacy to the users (Plate 3). Lack of privacy during the natures' call does not encourage the pit latrine users to properly dispose of the wastes into the pit. In some instances, the fecal matter is disposed of on the floor of the latrines (as observed in Plate 3), encouraging the breeding of vectors which then spread sanitationrelated diseases causing ill health to people in the surrounding areas.

Absence of covering lids may have encouraged insect infestation in the pit latrines that may have accounted for the outbreak of some diseases among the refugees as reported earlier. Slightly over a half (53.3\%) of the respondents reported that the insects present in the pit

Table 2 Use of pit latrines in Bidibidi refugee camp (respondent's questionnaire survey)

\begin{tabular}{llll}
\hline $\begin{array}{l}\text { Status of use } \\
\text { of latrine }\end{array}$ & $\begin{array}{l}\text { Number of members } \\
\text { in each household } \\
\text { who share pit latrines }\end{array}$ & Frequency & Percent \\
\hline Pit latrine not shared & & 102 & 59.6 \\
Pit latrine shared & $1-5$ & 51 & 29.9 \\
& $6-10$ & 7 & 4.1 \\
& 11 and above & 11 & 6.4 \\
Total & & 171 & 100.0 \\
\hline
\end{tabular}


Table 3 Materials used to construct pit latrines in Bidibidi refugee camp

\begin{tabular}{llll}
\hline Part of pit latrine & Building material & Frequency & Percent \\
\hline Pit latrine slab & Wattle and mud & 85 & 49.7 \\
& Plastic & 44 & 25.7 \\
& Iron bars, cement and sand & 24 & 14.0 \\
& Wood & 18 & 10.6 \\
Walls of pit latrine & Papyrus (reeds) & 64 & 37.4 \\
& Bricks and cement & 58 & 33.9 \\
& Wattle and mud & 36 & 21.1 \\
& Grass & 13 & 7.6 \\
Roof of pit latrine & Papyrus (reeds) & 62 & 36.2 \\
& Grass & 55 & 32.2 \\
& Iron sheets & 42 & 24.6 \\
& No roof & 12 & 7.0 \\
Door of pit latrine & Papyrus (reeds) & 101 & 59.0 \\
& Iron sheets & 48 & 28.1 \\
& Used sacks & 2 & 1.2 \\
& No door & 20 & 11.7 \\
\hline
\end{tabular}

latrines include houseflies (Musica domestica), while the rest reported cockroaches (Periplaneta americana). These might have acted as vectors of the various reported sanitation-related diseases, since the majority (68\%) of the pit latrines were in the proximity of the places of residence (Table 1 ).

About a third (36.2\%) and (32.2\%) of the pit latrines in Bidibidi refugee camp were roofed using papyrus (reeds) and grass (Plate 4) respectively. A quarter (24.6\%) of the roofs had iron sheets (Plate 3 ). However, there are those pit latrines that did not have roofs at all (Plates 1 and 3).

Slightly more than a half (59\%) of the doors of pit latrines were temporary, made of the papyrus (reeds) while some other pit latrines $(11.7 \%)$ did not have doors at all. Majority $(71.9 \%)$ of the pit latrines have either temporary screens made of papyrus and used sacks or

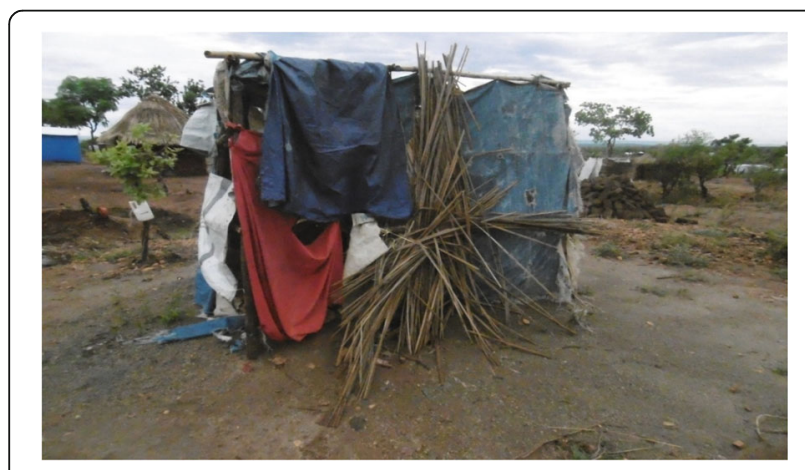

Plate $1 \mathrm{~A}$ pit latrine with shields made out of papyrus and old tarpaulins that work as a temporary wall

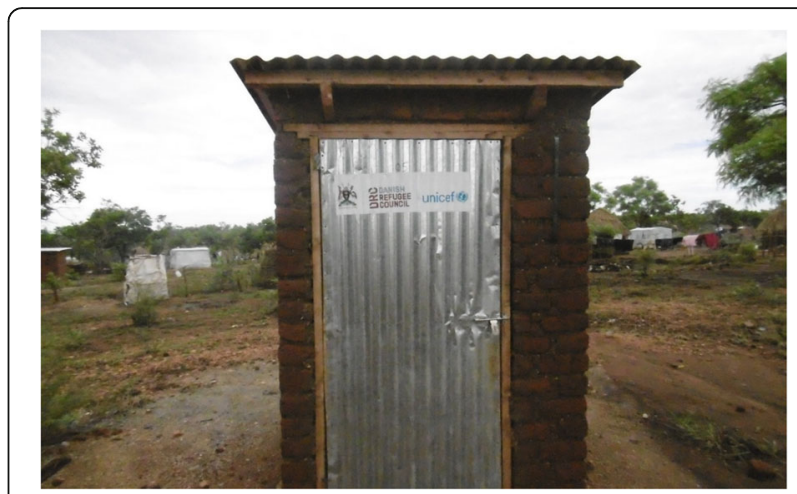

Plate 2 A pit latrine with walls made out of bricks and cement as recommended by Sphere Minimum Standards

have no door and hence could not securely close when someone is using them. Generally, the pit latrines constructed in Bidibidi refugee camp were of poor quality and were below the Humanitarian Sphere Standards which emphasizes that latrine floor should have a slab made of concrete of sand and cement, walls made of bricks and cement with proper doors and locks. Lack of doors and roofs on pit latrines did not offer maximum privacy to the users and could have encouraged the residents use the surrounding bushes to ease themselves, leaving the fecal matter exposed and encouraging vectors like houseflies transfer disease-causing organisms to residents' food. Exposed feces also have a potential of contaminating the surrounding water sources used for domestic use, especially during the rainy season.

A small proportion $(13.3 \%)$ of the respondents in the study area did not have a hand washing facility after visiting pit latrines. A bigger proportion (86.7\%) of the respondents had hand washing facilities. Of this proportion, $86.9 \%$ of the respondents reported that the hand washing facilities were located within $5 \mathrm{~m}$ from the pit latrines while $13.1 \%$ of the respondents asserted that the hand washing facilities were in distant places, more than $5 \mathrm{~m}$ from the pit latrines (Table 1). The hand washing

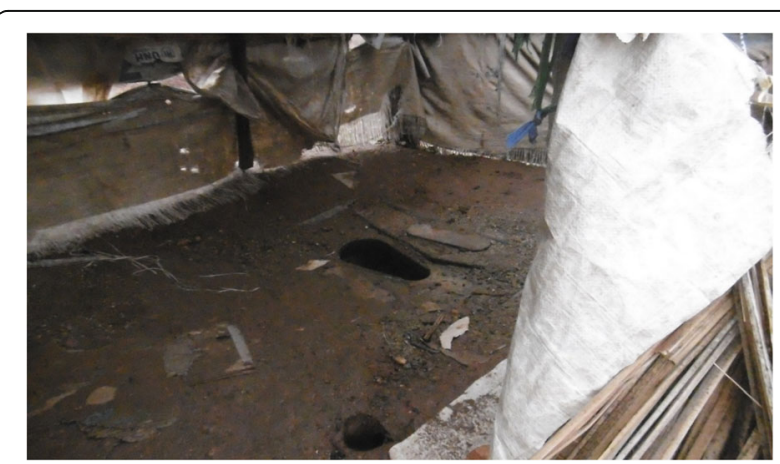

Plate $3 \mathrm{~A}$ pit latrine with temporally screens which work as walls and does not have a covering lid (C) 2017 


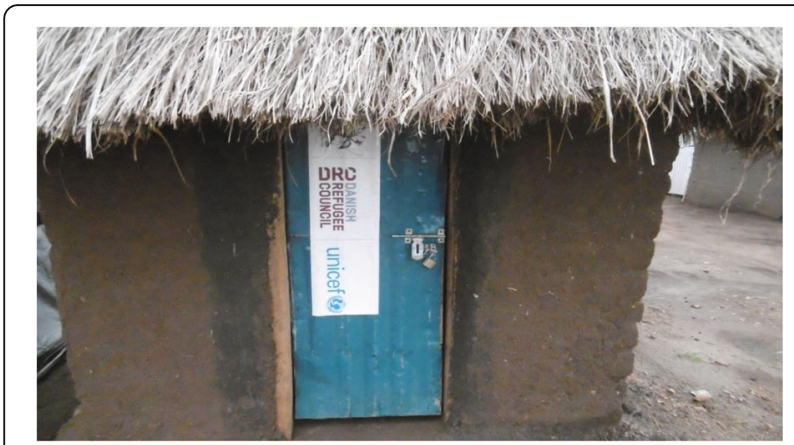

Plate 4 Pit latrine roofed using grass and it is lockable (C) 2017

facilities were either made of metal taps $(8.6 \%)$, or plastic (78.1\%) as shown in Plate 5 , and only $26.9 \%$ of the hand washing facilities had washing soap while the majority (73.1\%) had only water for washing after using the pit latrines (Table 4).

Solid waste disposal facilities as part of the sanitation facilities were also present in Bidibidi refugee camp (Table 1). Slightly over a half (57.7\%) of the respondents reported that the solid waste disposal facilities were located within a distance of $10 \mathrm{~m}$ from their place of residence, while a very small proportion $(14.8 \%)$ of residents stated that the solid waste disposal points were very distant (over $15 \mathrm{~m}$ ) from their residences. This could have contributed to some members in the refugee camp (49.1\%) not utilize the solid waste disposal facilities found in the study area to dispose of their solid wastes.

The solid waste disposal facilities present in the study area were rubbish pits $(41.1 \%, \mathrm{n}=88)$ as seen in Plate 6 , garbage skips $(5.1 \%, \mathrm{n}=11)$, and plastic or metallic containers $(4.7 \%, \mathrm{n}=10)$. The respondents $(49.1 \%, \mathrm{n}=105)$ who did not have access to solid waste disposal facilities indiscriminately disposed of their solid wastes in the bush, valleys, and roadside which may contribute as habitats for the vectors responsible for the spread of sanitation-related diseases.

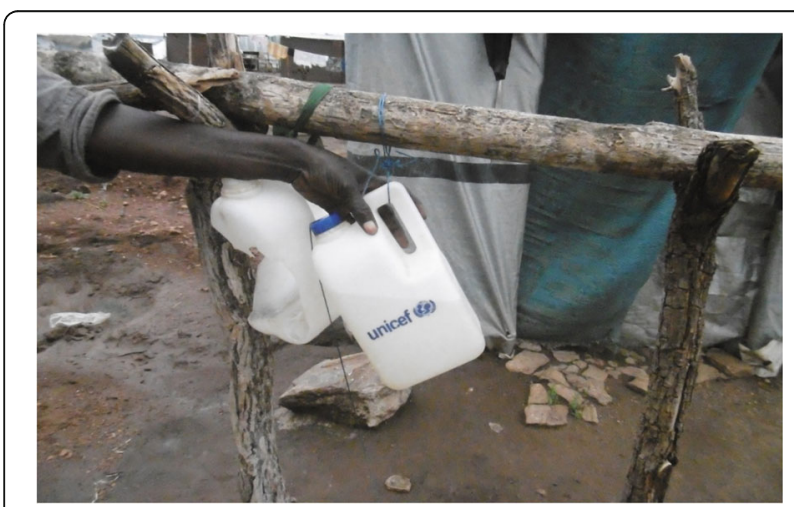

Plate 5 Hand washing facility in Bidibidi refugee camp (C) 2017
As it may be observed in Plate 6, the solid wastes in the rubbish pit are openly burnt to keep the amount at bay. This implies that since a sizable number of the households (41.1\%) use rubbish pits to dispose of the wastes, burning them may contribute to the spread of respiratory diseases among members in the refugee camps.

Thus, different sanitation facilities including pit latrines, solid waste disposal, and hand washing facilities are found in Bidibidi refugee camp and most of them are accessible by the residents. However, most materials used to construct the pit latrines do not conform to the minimum standards as put forward by the Minimum Sphere Standards while some solid waste disposal and hand washing facilities are inadequate to meet the needs of the big number of the refugees in the camp.

\section{Discussion}

The sanitation facilities found in Bidibidi refugee camp include pit latrines, hand washing facilities, and solid waste disposal areas. Pit latrines and hand washing facilities are the most common sanitation facilities found in Bidibidi refugee camp as reported by over $80 \%$ of the respondents. All the sanitation facilities found in Bidibidi refugee camp are located within a distance of $50 \mathrm{~m}$ from the area of dwellings and are accessible by majority of the respondents. This conforms to the Humanitarian Sphere Minimum Standards. The accessibility of the sanitation facilities to most refugees accounted to low incidences of sanitation-related diseases among the refugees in the camp and low incidences open defecation that may encourage the spread of sanitation-related diseases. A few households in the refugee camp share the use of pit latrines and because probably no household in particular is responsible for the latrines' cleanliness, this could have accounted for some spread of the sanitationrelated diseases among the refugees in the camp. The quality of the majority (86\%) of the pit latrines constructed in Bidibidi refugee camp is poor and is below the Humanitarian Sphere Minimum Standards. This is exhibited where the pit latrines are constructed using temporary slabs, temporary walls, and side screens, and others have no roofs and doors which did not offer maximum privacy and thus encouraged the users to improperly dispose of human wastes.

Temporary slabs as noted by Mara et al. (2010), WHO/UNICEF/JMP (2017) qualifies pit latrines to be regarded as unimproved and may lead to sanitationrelated diseases like diarrhea among the populations. The Sphere Minimum Standards as stated by the Sphere Project (2004), Mara et al. (2010) assert that there should be a minimum of one latrine per 20 people who share, and should be located at a maximum of $50 \mathrm{~m}$ from places of dwellings if optimum service delivery to 
Table 4 Hand washing facility and disinfection used in Bidibidi refugee camp (respondents' questionnaire survey)

\begin{tabular}{llllll}
\hline Presence of hand washing facility & Frequency & Percent & Disinfectant used & Frequency & Percent \\
\hline None & 28 & 13.3 & & 49 & 26.9 \\
Tap & 18 & 8.6 & Soap & No soap & 133 \\
Plastic & 164 & 78.1 & & 182 & 73.1 \\
Total & 210 & 100 & & 100 \\
\hline
\end{tabular}

residents is to be achieved. The results obtained from the study area shows that the sharing of the latrines and their distances from places of residence conform to the Sphere Minimum Standards except for a few households who share the use of pit latrines.

In terms of quality, the sanitation facilities especially the pit latrines and hand washing facilities found in Bidibidi refugee camp do not conform to the Humanitarian Sphere Minimum Standards and are regarded as unimproved. In relation to the results obtained, Mara et al. (2010) and Cairncross and Valdmanis (2006) argue that the unimproved pit latrines encourage the breeding of flies and mosquitoes, which as stated by Wolf et al. (2014) and Naughton and Mihelcic (2017) cause the spread of sanitation-related diseases among the residents. Pit latrines in Bidibidi refugee camp lack locks and yet the Sphere Project (2004) and Naughton and Mihelcic (2017) recommend that latrines should have inside locks, since modern and more advanced shelter as pointed out by Fekete et al. (2021) is paramount in the camps of displaced populations. Lack of inside locks in pit latrines is believed not to offer the user maximum privacy. The results are in agreement with Mulogo et al. (2018) who assert that a latrine that does not lock does not ensure the user adequate time and privacy to properly dispose of fecal matter.

Temporary screens used as walls of pit latrines in the study area does not provide privacy and at the same time do not allow users to defecate with dignity as pointed

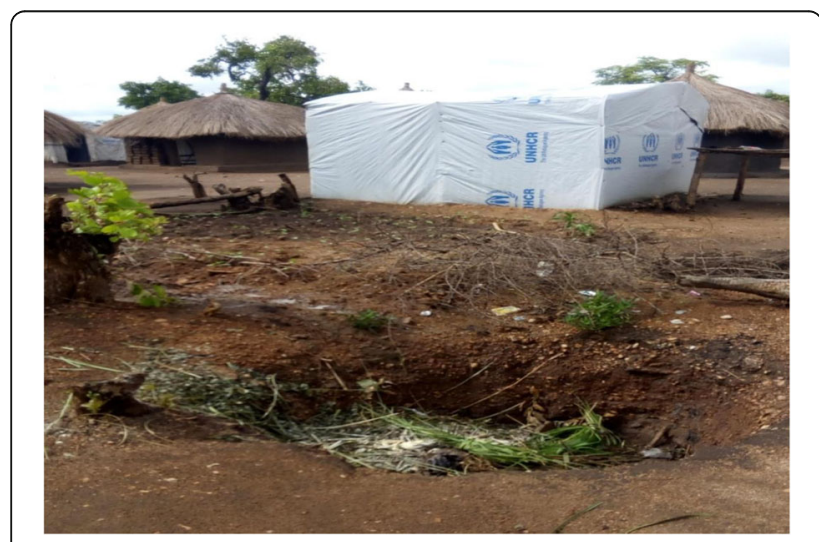

Plate 6 A rubbish pit used as a solid waste disposal facility (C) 2017 out by Cairncross and Valdmanis (2006) and WHO (2002). In relation, Fekete et al. (2021) argues that sheltering to the displaced populations does not only consider the logistical supply of essential services such as water, food, and others but also guaranteeing human dignity. The improper design of the pit latrines without proper fecal sludge management may contribute to the contamination of local environment and hence lowering the water quality (WWDR 2017; Naughton and Mihelcic 2017) that may contribute to the spread of sanitationrelated diseases. Birkmann et al. (2016) also states that when the critical infrastructure is compromised, reduced resilience and increased vulnerability manifest among the displaced persons toward extreme conditions which could lead to loss of lives.

Plastic containers were mainly used to store water for hand washing after latrine use in the study area. Very few taps with flowing water were available in the refugee camp. A few members in the refugee camp used soap while washing their hands after latrine use, the practice that may not be good enough to properly cleanse hands free from microbes which may be responsible for spreading germs. In light of these findings, Birkmann et al. (2016) point out that the non-functional critical infrastructures like water supply in areas occupied by the displaced persons results in increased human sufferings. This is because according to Griekspoor and Collins (2001) access to adequate resources is rarely met during large scale humanitarian emergency responses. In the same vein, the WHO (2013) states that absence of sufficient water among the displaced populations like the refugees is one of the causes of ill health. The Sphere Project (2004) suggests that water points should be within $500 \mathrm{~m}$ from the places of dwellings where water should be drawn for washing their hands after defecation in order to curb the spread of diseases. Some other authors like Mara et al. (2010) and Cairncross and Valdmanis (2006) posit that enabling easy access to water for hand washing and oral cleansing to members of the community is one of the humanitarian responses that could contribute to the reduction of public health risks. Cairncross and Valdmanis (2006) further assert that inadequate water supplies to people affected by crises enable them to be very susceptible to some infectious sanitation-related diseases like diarrhea. 
However, the results are not in agreement with statements written by some scholars like Griekspoor and Collins (2001) who stated that the populations living in places where the displaced have been settled must have access to life sustaining requirements including adequate water and sanitation.

The indiscriminate disposal of solid wastes in the respondents' dwellings may encourage the breeding of houseflies and mosquitoes as noted by Mara et al. (2010), Cairncross and Valdmanis (2006), and The Sphere Project (2004) which may escalate the spread of sanitation-related diseases. Flies as pointed out by Cairncross and Valdmanis (2006) are the main pathways for pathogens to infect humans.

\section{Conclusions}

A number of the sanitation facilities are found in Bidibidi refugee camp, Uganda. Such facilities mainly include pit latrines, hand washing facilities, and solid waste disposal areas. A bigger percentage of the refugees have been reported to access pit latrines where most of them are built within the recommended distance from places of dwellings as spelt out by the Humanitarian Minimum Sphere Standards. Although the observed coverage of the pit latrines in the study area is high; their design remains below the recommended Humanitarian Minimum Sphere Standards. The pit latrines do not provide adequate privacy in line with the norms of the users and they do not have adequate and regular supply of water. Some of them are shared by individuals in the refugee camp, which may create a sense of lack of ownership that may leave their sanitation condition wanting, a condition that may encourage the spread of sanitationrelated diseases.

Water for hand washing after use of pit latrines is accessed by most of the refugees in Bidibidi refugee camps and it is within the recommended distance as provided by the Humanitarian Minimum Sphere Standards. However, it was noted that a few taps with running water are available in the refugee camp. Little or no soap is available for the residents to effectively cleanse their hands after latrine use hence putting members of the local community at risk of contracting sanitation-related diseases.

Hence, for sanitation facilities in Bidibidi refugee camp to conform to the Humanitarian Minimum Sphere Standards, the design of pit latrines should be improved in order to offer adequate privacy and safety to the users, more taps with running water installed, soaps, and disinfectants for hand washing after use of pit latrine availed and more environmentally friendly methods of solid waste disposal encouraged among individuals living in the camp.

\section{Abbreviations}

B.C: Before Christ; DALYS: Disability adjusted life years; df: Degrees of freedom; E: East; JMP: Joint monitoring program; N: North; NRC: Norwegian Refugee Council; P: Probability; UNHCR: United Nations High Commissioner for Refugees; UNICEF: United Nations International Children's Emergency Fund; WASH: Water, sanitation, and hygiene; WHO: World Health

Organization; WSSCC: World Water Development Report; $x^{2}$ : Chi-square

\section{Supplementary Information}

The online version contains supplementary material available at https://doi. org/10.1186/s41018-021-00105-8

Additional file 1. Structured questionnaire for households

\section{Acknowledgements}

The study team acknowledges the support and participation of all the respondents who participated in this study. We thank the anonymous reviewers for their helpful comments in regard to the submitted manuscript.

\section{Authors' contributions}

Zaitun Bako participated in literature review and data collection. Alex Barakagira formulated the title and objectives of the study, participated in literature review, analyzed the collected data, and compiled all the information in the manuscript. Ameria Nabukonde participated in literature review and edited the manuscript. The authors read and approved the final manuscript.

Funding

There was no financial support or grant obtained for this study.

Availability of data and materials

All data supporting our findings are contained in the paper. Details of the full data may be accessed through the corresponding author.

\section{Declarations}

Competing interests

The authors declare that they have no competing interests.

Received: 15 September 2020 Accepted: 28 June 2021

Published online: 14 July 2021

\section{References}

Bill and Melinda (2016) Water, Sanitation and Hygiene: strategy overview. 19912021 Bill and Melinda Gates Foundation. gatesfoundation.org/our-work/ programs/global-growth-and-opportunity/water-sanitation-and-hygiene

Birkmann J, Wenzel F, Greiving S, Garschagen DV, Nowak W, Welle T, Fina S, Goris A, Rilling B et al (2016) Extreme events, critical infrastructures, human vulnerability and strategic planning: emerging research issues. J Extreme Events 3(4):1650017. https://doi.org/10.1142/s2345737616500172

Bryman A (2004) Social research methods. Great Clarendo Street, Oxford 0x2 6DP: Oxford University press

Cairncross S, Valdmanis V (2006) Water supply, sanitation and hygiene promotion. In: Jaminson DT, Breman JG, Measham RA et al (eds) Disease control priorities in developing countries, 2nd edn. Oxford University Press and World Bank, New York, pp 771-792

Eliasson J (2013) Water for all. UN Deputy Secretary General on adoption 24th July 2013 of UN General Assembly Resolution

Fekete A, Bross L, Krause S, Neisser F, Tzavella K (2021) Bridging gaps in minimum humantarian standards and shelter planning by critical infrastructures. Sustainability. 13. Page 849. https://doi.org/10.3390/su1302 0849, 2

Griekspoor A, Collins S (2001) Raising standards in emergency relief: how useful are Sphere minimum standards for humanitarian assistance? BMJ 2001: 323 Page 740-742

Hoggart K, Lee L, Davies A (2002) Researching human geography. Arnold, London Hyman D, Mcnight J, Higdon F (2001) Doing democracy, conflict and consensus, strategies for citizen, organisation, and communities. Education Press, New York 
Lindlof TR, Taylor CB (2011) Qualitative communication research methods. 3rd Ed. SAGE Publications, Inc. 2455 Teller Road, Thousand Oaks, California, 91320

Mara D, Lane J, Scott B, Trouba D (2010) Sanitation and health. J PLoS Med 7(11): e1000363. https://doi.org/10.1371/journal.pmed.1000363

Moe CL, Rheingans RD (2006) Global challenges in water, sanitation and health. J Water Health (2006) 4 (S1): 41-57 https://doi.org/https://doi.org/10.2166/wh.2 006.0043

Mulogo EM, Matte M, Wesuta A, Bagenda F, Apecu R, Ntaro M (2018) Water, Sanitation and hygiene. Service availability at rural health care facilities in southwestern Uganda. J Env. And Pub. Health 1-7. https://doi.org/10.1155/2 018/5403795, 2018

Naughton C, Mihelcic JR (2017) Introduction to the importance of sanitation. In: Rose JB, Jimenez-Cisneros B, (eds) Global Water Pathogen Project http:// www.waterpathogens.org (Rose JB, Jimenez-Cisneros B) (eds) Part 1. The Health Hazards of Excreta. Theory and Control. http://www.waterpathogens. org/book/introduction. Michigan State University, E. Lansing, ML, UNESCO. Accessed 29 Apr 2020

Pruss-Ustun A, Bos R, Gore F, Bartram J (2008) Safer water, better health: costs, benefits and sustainability of interventions to protect and promote health. World Health Organization, Geneva

Sarantakos S (2005) Social research. Houndmills, Basingstoke, Hampshire RG21 6XS and 175 Fifth Avenue, New York, N.Y.10010 Palgrave MacMillan

The Sphere Project (2004) Humanitarian charter and minimum standards in disaster response. Geneva, Switzerland, The Sphere Project http://www. sphereproject.org. Accessed 27 Apr 2020

UNHCR (2016) UNHCR Report. Department of Health. Yumbe District Local Government, Uganda

UNICEF and WHO (2004) Meeting the MDG drinking water and sanitation target: a mid-term assessment of progress. UNICEF/WHO, Geneva, Switzerland

WHO (2002) Reducing risks, promoting healthy life: World Health Report 2002. Geneva: WHO

WHO (2012) Global costs and benefits of drinking-water supply and sanitation interventions to reach MDG target and universal coverage. WHO. Geneva, Switzerland

WHO (2013) Water, sanitation, hygiene and health. Unit Avenue Appia 20.1211 Geneva 27 Switzerland

WHO (2017) Diarrhoel disease: Fact sheet. Geneva: World Health Organisation (WHO)

WHO and UNICEF (2015) Progress on sanitation and drinking water. WHO, Geneva and UNICEF, New York

WHO/UNICEF JMP (2015) WHO/UNICEF Joint Monitoring Programme (JMP) for water supply and sanitation

WHO/UNICEF Joint Monitoring Programme (JMP) (2017) WASH in the 2030 agenda: new indicators for water, sanitation and hygiene

Wolf J, Pruss-Ustun A, Cumming O, Bartram J, Bonjour S, Cairncross S, Clasen T, Colford JM, Curtis V, De France J, Fewtrell L, Freeman MC, Gordon B, Hunter PR, Jeandron A, Johnston RB, Mäusezahl D, Mathers C, Neira M, Higgins JPT (2014) Systematic review. Assessing the impact of drinking water and sanitation on diarrhoeal disease in low- and middle-income settings. Systematic review and Meta-regression. Trop. Med. Int. Health 19(8):928-942. https://doi.org/10.1111/tmi.12331

World Water Development Report (WWDR) (2017) Wastewater: the untapped resource. United Nations Educational Scientific and Cultural Organisation (UNESCO). Paris, France

WSSCC (2004) Global WASH Forum 2004-Water, Sanitation and Hygiene for all. Solutions and actions, local and national. Dakar, Kaolack, Senegal

Yamane T (1967) Statistics. An Introductory Analysis, 2nd Ed. New York. Harper and Row

\section{Publisher's Note}

Springer Nature remains neutral with regard to jurisdictional claims in published maps and institutional affiliations.

\section{Submit your manuscript to a SpringerOpen ${ }^{\circ}$ journal and benefit from:}

- Convenient online submission

- Rigorous peer review

- Open access: articles freely available online

- High visibility within the field

- Retaining the copyright to your article

Submit your next manuscript at $\boldsymbol{\nabla}$ springeropen.com 